\title{
DISCUTINDO MODELOS DE VISÃO UTILIZANDO A HISTÓRIA DA CIÊNCIA
}

\author{
Boniek Venceslau da Cruz Silva
}

Licenciatura Plena em Física pela UFRN/ Mestrando em Ensino de Ciências Naturais e Matemática (PPGECNM-UFRN) / Grupo de Pesquisa em Ensino de Ciências e Cultura (UFRN) / Grupo de Pesquisa em Ensino de Física e de Astronomia (UFRN)/

Professor da Escola Estadual Presidente Roosevelt (SEEC).

boniekvenc@yahoo.com.br

\section{RESUMO}

Embora perguntar o porquê enxergamos um objeto venha a nos parecer uma pergunta tão trivial, em determinadas situações é bastante comum as explicações advindas do público escolarizada ou não serem totalmente contraditórios a explicação científica atual. Em alguns casos, as respostas dadas, por exemplo, em sala de aula, são encaradas como erros grosseiros, sendo repelidos e rechaçados pelos professores de ciências. O objetivo deste trabalho é mostrar que, em muitas situações, existe uma correlação entre os erros apresentados pelos alunos em sala de aula com modelos desenvolvidos por cientistas em épocas passadas. Portanto, ciente desta correlação, o docente poderá desenvolver práticas que aproximem às respostas dos alunos a explicação científica atual. Objetivamos mostrar uma possibilidade de se trabalhar um conceito científico bastante discutido, tomando como ponto de partida a vivência dos alunos.

PALAVRAS-CHAVE: História da Ciência, Óptica, Modelos de Visão, Ensino de Física

\section{DISCUSSING MODELS OF VISION USING THE HISTORY OF SCIENCE}

\begin{abstract}
While asking why we see an object will appear in a question so trivial, in certain situations is very common explanations resulting from the public educated or are not totally contradictory to the current scientific explanation. In some cases, the answers given, for example, in the classroom, are seen as gross errors and is repelled and repulsed by science teachers. The objective of this work is to show that in many situations, there is a correlation between the errors made by students in the classroom with models developed by scientists in the past. Therefore, aware of this correlation, the teacher can develop practices that bring the students' responses to current scientific explanation. Our purpose is a possibility to work with a scientific concept much discussed, taking as its starting point the experience of students.
\end{abstract}

KEYWORDS: History of Science, Opticks, Vision Models, Teaching of Physics 


\section{DISCUTINDO MODELOS DE VISÃO UTILIZANDO A HISTÓRIA DA CIÊNCIA}

\section{INTRODUÇÃO}

A partir da década de 80 do século passado, intensificam-se, na área de Ensino das Ciências Naturais, as pesquisas relacionadas às concepções alternativas dos alunos. Estas pesquisas evidenciavam que os alunos possuíam uma forma particular de enxergar os fenômenos naturais: geralmente, as suas explicações, para tais fenômenos, eram diferentes das explicações de natureza científica (SILVA; SILVA; NUÑEZ, 2004).

Não distante desta época e destas discussões surgem novas propostas que adota a História e a Filosofia da Ciência (HFC) como um elemento motivador e propulsor de novas práticas em sala de aula. Desta forma, poderia promover o diálogo entre as ideias desenvolvidas pelos alunos em sala de aula e as concepções científicas, sejam elas do passado ou as atuais.

Para os autores (VANNUCCHI, 1996; MATTHEWS, 1995; SILVA, 2009) que problematizaram o uso da HFC no ensino de ciência, para eles a sua inserção poderia promover um estudo de conceitos e teorias científicas de forma mais agradável, resgatando fatores sobre o fazer científico esquecidos em algumas práticas, por exemplo: o dia-a-dia do cientista, o papel de fatores sociais, políticos, religiosos, econômicos na formulação de teorias, a falibilidade dos cientistas, a contribuição de outros povos na formação de uma teoria, entre outros. Ainda na extensa literatura (VANNUCCHI, 1996; SOUZA, 2008; SILVA, 2008; SILVA; MARTINS, 2009a; SILVA; MARTINS, 2009b) é possível encontrar várias maneiras de se trabalhar a HFC na sala de aula, citemos algumas: textos, júris simulados, debates e encenações teatrais.

Diante disto, o objetivo deste trabalho é apresentar uma correlação das interpretações dadas pelos alunos em sala de aula com explicações científicas apresentadas por cientistas em épocas passadas, esperamos assim, por fim, oferecer subsídios aos docentes para que possam não só repensar a sua prática, mas sim elaborar novas formas estratégias de trabalhar o conceito em questão.

\section{O ESTUDO DA LUZ E DA VISÃO NA ANTIGUIDADE CLÁSSICA}

Os estudos sobre a Óptica situados anteriormente ao século XVII são baseados nas propriedades da luz (tratamento geométrico) e desenvolvimento de aparatos ópticos. Já as produções de hipóteses sobre a natureza da luz ficavam em segundo plano, e seus questionamentos tinham especulações puramente metafísicas (CROMBIE, 1980; VANNUCCHI, 1996).

Na Antigüidade, a luz, devido a sua importância, foi associada a divindades em algumas civilizações. Para os antigos hebreus, quem a fez foi Deus, como é visto nas primeiras páginas do livro do Gênesis. Para os egípcios, ela era uma deusa - Maât -, filha do deus Sol - Rá. Somente com os Gregos, a luz passa a não mais ser vista sob esse aspecto, e ganha uma característica mais objetiva com o surgimento de perguntas intrigantes para a sociedade grega antiga. Segundo Bassalo (1986), a pergunta básica partia do questionamento dos gregos antigos em compreender o que existe entre o espaço dos nossos olhos e o objeto visto. 
Para responder a isso foram criados três modelos distintos: a tese dos raios visuais, segundo a qual os olhos emitiam partículas luminosas; a noção de que os olhos recebiam raios emitidos pelos corpos; e a terceira concepção, formulada pelo filósofo grego Platão (428-348 a.C), de que a visão de um objeto era devida a três jatos (raios) de partículas: um proveniente dos olhos, outro do objeto e o último da fonte iluminadora. De acordo com Bassalo (1986, p.139), um feixe de raios luminosos sai dos olhos até o objeto a ser visto, combinando-se com raios emitidos pela fonte e, por fim, retornando aos olhos. Em contraste com esta idéia de emissão de raios, os estóicos ${ }^{1}$ tinham sugerido que a visão se dava por raios de luz que entravam nos olhos desde o objeto

Em relação à formação das imagens, diz a idéia pitagórica, que a imagem era formada por um fluxo emitido pelos olhos. A idéia platonista acreditava no encontro entre feixes dos olhos e os objetos. Todas as concepções filosóficas acima descritas utilizavam à idéia da luz composta por partículas.

No âmbito das visões atomistas gregas, destacamos as idéias de Leucipo (480-420 a.C) e Demócrito $^{2}$ (460-370 a.C),os quais entendiam a luz como sendo composta por átomos arredondados e velozes que se deslocavam no vazio. A visão dar-se-ia devido a um fluxo de partículas emanado dos objetos e assimilado pelos nossos olhos. Tanto Demócrito como os atomistas da época detinham um pensamento de percepção sensorial, onde os objetos emitiam átomos, que formavam uma imagem dos objetos, percebida, posteriormente, pelos órgãos da visão para formar, por fim, a imagem (GARCÍA et al., 2007).

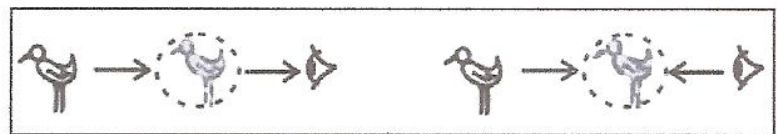

Figura 1 - Modelos de visão para Demócrito (à esquerda) e para Platão (à direita), apud García et al., (2007).

Aristóteles (384-322 a.C) entendia que não havia os átomos, e, sim, uma substância, que preenchia todo o espaço - o éter. Ele foi um dos primeiros a tentar dar uma explicação não corpuscular para a natureza da luz. Ele crítica o modelo de visão atomista, por exemplo, se os objetos emitem imagens, o que ocorre quando se cruzam no espaço? Como pode caber a imagem de um grande objeto na pupila?

Aristóteles compreendia a natureza vibratória do som, então, tentou compará-los para achar uma resposta para a luz. Para ele, a luz era resultado da atividade de um determinado

\footnotetext{
${ }^{1}$ O Estoicismo é uma doutrina filosófica que afirma que todo o universo é corpóreo e governado por um Logos divino: a alma. Ela está identificada com este princípio divino, como parte de um todo ao qual pertence. Este logos ordena todas as coisas, onde tudo surge a partir dele e de acordo com ele.

${ }^{2}$ Observem que do ponto de vista cronológico, não podemos colocar Leucipo e Demócrito juntos. Leucipo era de Mileto e suas preocupações eram cosmológicas, enquanto Demócrito, de Abdera, tinha ambições mais éticas. Entretanto, os colocamos juntos, pois compartilham um mesmo conjunto de obras: a escola de Abdera. É bastante complexo identificar o que foi escrito por um ou outro, ou ainda o que é fruto de outros membros da escola.
} 
meio, cuja vibração provocaria o movimento de humores presentes nos olhos (ROCHA, 2002). Para ele a Óptica estava subordinada a Geometria, e foi justamente o conhecimento dos "Elementos" de Euclides e das "Cônicas" de Apolônio que alavancariam o progresso da óptica, principalmente na Idade Média (CROMBIE, 1980).

Para Empédocles (435-430 a.C), a luz era um movimento transmitido que necessitava de tempo para transmitisse (CROMBIE, 1980). Mas, como relata Crombie (1980), Empédocles não avançaria nos estudos sobre onde (como seria este meio) a luz se transmitiria.

Para os contínuos - uma corrente filosófica contrária à idéia do atomismo em relação à explicação dos fenômenos da natureza - a visão é produto da luz, que sai da alma do observador, propaga-se pelo corpo através do "pneuma”, que o preenche, até alcançar os nossos olhos.

Esta concepção sobre a propagação da luz em um meio é oriunda dos estóicos, e suscitava um desconforto em relação à idéia dos atomistas, que abordavam uma natureza descontínua da matéria (ROSA, 2005). A física dos contínuos tinha na sua raiz, a natureza contínua da matéria.

Para Vannucchi (1996), as contribuições dos gregos para estudos sobre a natureza da luz se mostraram de natureza metafísica. Entretanto, foi uma ou outra destas teorias dos raios, que implicariam na definição da trajetória retilínea dos mesmos, a qual foi adotada por geômetras gregos como Euclides e Ptolomeu. Estes estudos fizeram com que a óptica progredisse a uma posição igual a da Astronomia e da Mecânica, que eram consideradas as ciências físicas mais avançadas da Antiguidade (CROMBIE, 1980).

No início do século II d.c, Cláudio Ptolomeu (85 - 165), ainda na Antiguidade, descreve as leis da reflexão e da refração em seu livro “Ótica”. Ele também descreve a refração solar da luz e das estrelas ao atravessar a atmosfera terrestre. Ptolomeu, ainda, teria realizado o primeiro estudo detalhado da lei da refração (BASSALO, 1986; CHALMERS, 1994).

\section{DISCUSTINDO A LUZ NA IDADE MÉDIA}

As investigações dos antigos cientistas árabes - Alhazen (965-1039), Avicena (980-1037) e Averroës (1126-1198) foram seqüências dos trabalhos de Ptolomeu (CROMBIE, 1980; CHALMERS, 1994). Depois da queda do império romano, cientistas árabes aperfeiçoaram os seus estudos sobre a óptica que foram de influência significativa sobre os ópticos da Idade Média.

Por volta de 1038 d.c, Alhazen melhoraria as leis da reflexão e da refração, e rejeitaria a idéia de raio visual, adotando uma postura mais próxima à de Aristóteles (BASSALO, 1986; ROCHA, 2002). 
Para Alhazen $^{3}$, a luz deveria intervir na visão, ela era considerada uma entidade independente do objeto e do olho. A visão, nos diz García et al., (2007), segundo Alhazen, consistia na formação de uma imagem óptica no interior do olho, que funcionava como uma câmara escura, onde os raios de luz emitidos por cada ponto do corpo atravessaria a pupila e formaria um ponto correspondente da imagem no espelho da câmara.

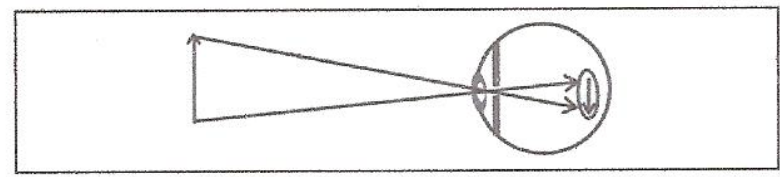

Figura 2 - Modelo de visão de Alhazen apud García et al,. (2007)

Contudo, os estudos sobre a ótica ainda permaneciam como uma característica marcadamente filosófica. Para Crombie (1980), os trabalhos de Alhazen são considerados a fonte principal da Óptica no Ocidente Medieval (VANNUCCHI, 1996).

O período inicial da idade média é marcado pela substituição dos ideais gregos de compreensão da natureza (do próprio homem) para a de analogias com as verdades religiosas e morais. Nas palavras de Crombie, este período se resume no "desejo de uma paz imperturbável, conquistada somente pela mente liberta das dependências da matéria e da carne” (CROMBIE, 1980).

Embora outras ciências como a Astronomia e Mecânica apresentassem avanços significativos nesta época, outra ciência viria a mostrar um desenvolvimento notável, a Óptica durante os séculos XIII e XIV, muito devido aos estudos dos árabes, recebeu uma atenção especial, principalmente, dos defensores do neoplatonismo agostinianos em Filosofia. Isto se dava pela seguinte razão: a luz era vista para Santo Agostino, e outros neoplatónicos, bem próxima a uma graça divina de iluminação do intelecto humano pela verdade divina. Outro fator preponderante era que a luz poderia ser reduzível a tratamentos matemáticos (CROMBIE, 1980).

Segundo Martins (1995), Santo Tomás de Aquino (1225-1274), que funde as teses da Igreja com a filosofia de Aristóteles, discute a própria noção de luz, tanto no seu sentido físico quanto metafísico. Para falar sobre sua imaterialidade, ele se vale de um bom argumento: dois corpos não podem ocupar o mesmo lugar ao mesmo tempo, porém a luz ou qualquer objeto transparente pode. Portanto, a luz não seria algo material (MARTINS, 1995). Provavelmente, sua aversão à materialidade da luz se assemelha as concepções de Aristóteles sobre a sua natureza.

\footnotetext{
${ }^{3}$ Observem que o modelo adotado por Alhazen, já reflete o utilizado atualmente pela ciência. Como podemos observar na figura 2, o raio de luz chega ao olho. É importante relacionar também o binômio visão-luz, que em alguns modelos anteriores foram desconsiderados, ou seja, não leva em conta a presença de uma fonte luminosa. Este problema, relacionado à ausência do binômio visão-luz, é costumeiramente encontrado nas explicações dos alunos diante do problema lançado: como você enxerga um objeto? Para maiores esclarecimentos, veja: Silva; Martins, 2009a.
} 
Entre os escritores da óptica do século XIII merece destaque Robert Grosseteste (11681253). Ele entendia que a luz era a primeira forma corporal das coisas materiais. Segundo Grosseteste, as mudanças no universo poderiam ser atribuídas, em última instância, a atividade desta forma corpórea fundamental. Por exemplo, o calor, as influências astrológicas e a ação mecânica deviam-se a esta propagação desta forma corpórea fundamental. Esta sua interpretação da luz viria a influenciar Roger Bacon (1214-1294) e outros autores, e todos eles contribuiram no esclarecimento não só da ação da luz, mas também a sua natueza (CROMBIE, 1980).

Todavia, a característica do conflito, ainda, permaneceria em um âmbito filosófico, em que as idéias aristotélicas e as pitagórico-platonistas continuariam a circular até o século XVII.

Chegando ao século XVII, os estudos sobre a óptica, teriam uma atenção em especial em explicar o que seria a luz. Esse período, e o que se segue, ficaria marcado, em especial, pelos embates científicos de cientistas influentes como Isaac Newton e Robert Hooke, que pretendiam esclarecer a natureza da luz. Por não se tratar do objeto de estudo desse trabalho não discutiremos sobre esse tema ${ }^{4}$.

\section{PROBLEMAS ENFRENTADOS AO ENSINAR ÓPTICA}

A literatura especializada (OSBORN et al, 1993; GIRCOREANO; PACCA, 2001; DEDES, 2005; GARCIA et al, 2007) apontam que os alunos trazem para a sala de aula conceitos e idéias prévias em desacordo com os científicos. Nos dias atuais, o número de informações relevantes, que podem ser utilizadas em sala de aula, aumentou de forma significativa. Como relatam Gircoreano e Pacca (2001), as concepções alternativas na óptica são abundantes e de natureza bastante complexa.

Em alguns casos, o objetivo da aprendizagem em óptica se restringe ao estudo de medidas de ângulos, aplicação da trigonometria e, em muitos casos, memorização de fórmulas (GIRCOREANO; PACCA, 2001; GARCIA et al, 2007; SILVA; MARTINS, 2009a). Especificamente, os mecanismos da visão e a explicação física do que é a luz ficam em segundo plano, sendo suas características e propriedades renegadas. O que é repassado aos alunos, verdadeiramente, são definições de raios, ângulos e fontes luminosas. Segundo Dedes (2005), este tipo de abordagem somente reforça as concepções alternativas. O autor lista algumas concepções ligadas ao mecanismo da visão. São elas: (a) Emissão simples da imagem: o olho possui uma luminosidade independente da fonte, fazendo a sua presença desnecessária; (b) Emissão cooperativa: o objeto constitui o epicentro do processo de visão, uma vez que é simultaneamente iluminado tanto pela fonte como pelo olho do observador; (c) Emissão estimulada (sem fonte luminosa): este sistema exige a passagem de luz direta desde o objeto até o olho; (d) Emissão estimulada com reflexão (sem fonte luminosa): decorrente do modelo anterior, nele a luz é refletida na superfície do objeto e volta para o olho, transportando a imagem; (e) Dupla iluminação: a fonte ilumina simultaneamente os olhos e o objeto. O olho mira o objeto, não existe conexão com raios luminosos e a fonte luminosa.

\footnotetext{
${ }^{4}$ Para maiores esclarecimentos, veja: Silva, 2008 e Silva, 2009.
} 
Diante de todas essas informações, surge uma pergunta intrigante para o ensino de Ciências, em geral, e de Física, em particular. O que fazer diante de tantas informações trazidas pelos alunos? Qual deve ser a postura do professor perante as concepções alternativas dos alunos?

Ressaltemos que, em muitos casos, o professor não consegue identificar as concepções alternativas, confundindo-as com erros e as ignorando. Freire (2008) nos alerta que devemos respeitar os saberes trazidos pelos alunos, pois estes conhecimentos são socialmente construídos e assimilados pelos discentes, fazendo sentido nas suas aplicações do dia-a-dia.

O processo ensino-aprendizagem, em que o aluno é receptor e o professor é emissor, não levam, em muitos casos, em consideração as concepções alternativas trazidas pelos alunos, estas, muitas vezes, frutos de uma herança sócio-cultural, mostrando ser de suma relevância para o aluno.

Em algumas ocasiões, este processo é marcado pelo dogmatismo do professor, em que são distribuídos conhecimentos efêmeros e desordenados, marcados pelo signo da autoridade (LOPES, 1993).

Defendemos que a função do professor é promover um diálogo entre os saberes dos alunos (muitas vezes repletos de concepções alternativas) e a cultura científica. Julgamos ser inconcebível o aluno acreditar, por exemplo, em uma lei Física, sem estar convencido da racionalidade dela.

Na tabela abaixo, mostramos uma possível correlação que pode ser feita entre as concepções alternativas mostradas pelos alunos e alguns modelos de visão desenvolvidos no decorrer da história. Observe que a correlação embora não seja de forma direta, torna-se importante para o professor que deseje trabalhar os erros conceituais sobre esse assunto.

Tabela 1: Possível correlação entre as concepções alternativas dos alunos e os modelos de visão desenvolvidos por cientistas no passado.

\begin{tabular}{|c|c|}
\hline Concepção Alternativa & $\begin{array}{c}\text { Modelo desenvolvido por cientistas ou filósofos em } \\
\text { épocas anteriores }\end{array}$ \\
\hline Emissão Cooperativa & Modelo de Platão \\
\hline $\begin{array}{c}\text { Emissão estimulada sem } \\
\text { fonte luminosa }\end{array}$ & Modelo de Leucipo e Demócrito \\
\hline
\end{tabular}

Embora Dedes (2005) não relate a presença da concepção alternativa: o olho emite um feixe luminoso, esta é explicitada por outros autores. Por exemplo, Silva e Martins (2009a) mostram uma correlação entre essa explicação e o modelo desenvolvido por Pitágoras. 
Ainda podemos fazer outras referencias com outros autores como Gircoreano e Pacca (2001), onde ele relata o modelo de banho de luz, onde é comum os alunos relatarem que a luz é responsável por iluminar tanto o objeto como o olho humano, aproximando do que é argumentado por Dedes (2005).

Portanto, atividades que possuam, no seu arcabouço, discussões sobre a História e a Filosofia da Ciência podem surgir como elemento diferencial na hora do docente trabalhar as concepções alternativas dos alunos, pois a sua inserção no ensino de ciências é capaz de evidenciar aos discentes que os seus erros foram recorrentes em outras épocas, dando-lhes uma maior possibilidade de reconhecer os limites dos seus modelos, além de propiciar uma maior racionalidade na hora da aceitação do modelo científico.

Na literatura especializada podemos encontrar várias maneiras de se utilizar a HFC ${ }^{5}$ como pano de fundo de discussões, que visem trabalhar tanto a discussão da teoria cientifica vigente como as concepções alternativas mostradas pelos alunos. Alguns exemplos de atividades de ensino são o uso de textos históricos, o júri simulado, peças teatrais e debates.

\section{CONCLUSÃO}

É preciso os professores saber lidar com os possíveis erros conceituais, sejam eles habituais, no sentido de o professor conhecer o erro apresentado pelo aluno, ou erros nos quais o docente se depara pela primeira vez.

É interessante notar, também, em alguns casos, as respostas dadas pelos alunos, dependendo da situação, podem ou não serem considerados equívocos quando comparados a modelos e teorias propostos por cientistas influentes no passado, como podemos notar no nosso estudo histórico.

A História da Ciência mostra que os erros, em alguns momentos, não são equívocos que podem prejudicar o prosseguimento da ciência. E ainda como aponta Bachelard (1996), o erro faz parte da prática da ciência. Entretanto, a epistemologia mais tradicional trata o erro científico como algo a ser evitado, desvinculando-o de qualquer processo de evolução. Algo parecido acontece também com os docentes quando ignoram os erros dos alunos, tratando-os como erros capitais e sem importância.

Bachelard (1996), por outro lado, considera o erro como inevitável, e como parte integrante das etapas a serem superadas. É o afastamento gradativo dos erros que permite o avanço do conhecimento. Portanto, uma postura semelhante deve ser assumida pelo docente quando se deparar com os erros conceituais dos alunos.

Finalmente, para os alunos estes erros favoreceram o descobrimento de novos fatos, que se mostraram de suma importância no desenvolvimento de um conceito científico.

\footnotetext{
${ }^{5}$ Para maiores detalhes, veja: Silva; Martins, 2009; Silva; Martins, 2009a.
} 
Mas, sabemos da dificuldade de inserir temas como este no ensino de Ciências. Como alerta Martins (2007), existem fatores que dificultam a sua inserção no ensino, por exemplo: a falta de materiais de qualidade para o seu uso no ensino de ciências; o engessamento de currículos, quase que exclusivamente voltados para vestibulares ${ }^{6}$, e a falta de preparação dos professores, entre outros.

Na nossa prática, como professores, tentamos elaborar textos que consigam, tomando como ponto de partida a HFC, trabalhar a transformação dos modelos de visão até o modelo de Alhazen, que representa o modelo cientifico vigente.

Acreditamos que a HFC possa servir como subsídios para elaboração não só de textos históricos para a utilização nas salas de aulas, mas como ferramenta para criação de novas práticas pedagógicas. Diante disto, esperamos que esse e outros trabalhos que tenham como preocupação utilizar a HFC em estratégias didáticas possam preencher um espaço que, ainda, é reduzido em nossos livros textos, e, principalmente, em nossas salas de aula.

\section{AGRADECIMENTOS}

Agradeço aos pareceristas e ao editor da revista, que mesmo anônimos contribuiram enormemente com este trabalho.

\section{REFERÊNCIAS}

BACHELARD, G. A formação do espírito cientifico: contribuição para uma psicanálise do conhecimento. Tradução de Estela dos Santos Abreu. Rio de Janeiro: Contraponto, 1996. 316p.

BASSAlO, J. M. F. A Crônica da Ótica Clássica. Caderno Catarinense de Ensino de Física, Florianópolis, v. 3, p.138-159, 1986.

CHALMERS, A. F. A fabricação da ciência. São Paulo: Ed. UNESP, 1994.

CROMBIE. A.C. Historia de la Ciência: de San Agustín a Galileo. Madrid. Alianza Editorial, v.1, 1980.

DEDES, Christos. The Mechanism of vision: conceptual similarities between historical models and Children's representations. Science \& Education, v.14, p. 699-712, 2005.

FREIRE, Paulo. Pedagogia da Autonomia. São Paulo: Editora Paz e Terra, 2008.

GARCÍA, Luís Osuna et al. Planificando la enseñanza problematizada: el ejemplo de la óptica geométrica em educación secundaria. Enseñanza De Las Ciencias, Madrid, v. 2, n. 25, p.277-294, 2007.

\footnotetext{
${ }^{6}$ Entretanto, defendemos que uma abordagem de tal natureza favorece a aprendizagem de conceitos científicos. Portanto, também, preparam para os vestibulares.
} 
GIRCOREANO, José Paulo; PACCA, Jesuína Lopes de Almeida. O ensino da óptica na perspectiva de compreender a luz e a visão. Caderno Catarinense de Ensino de Física, Florianópolis, v.18, n.1, p.26-40, 2001.

IPARRAGUIRRE, Lorenzo Marcos. Uma propuesta de utlización de la historia de la ciencia em la enseñanza de um tema de Física. Enseñanza de las ciencias. v.25, n.3, p423-434, 2007.

LOPES, Alice Ribeiro Casimiro. Contribuições de Gaston Bachelard ao ensino de ciências. Enseñanza de las Ciencias, Madrid, v.11, n.3, p.324-330, 1993.

MARTINS, André Ferrer Pinto. História e Filosofia da Ciência no ensino: há muitas pedras nesse caminho... Caderno Brasileiro de Ensino de Física, Florianópolis, v. 24, n. 1, p.112-131, 2007.

MARTINS, R. A. O Universo: teorias sobre sua origem e evolução. In: O pensamento medieval e o renascentista. São Paulo: Moderna, 1995. p. 61-73

MATTHEWS, Michael R. História, Filosofia e Ensino de Ciências: a tendência atual de reaproximação. Caderno Catarinense de Ensino de Física, Florianópolis, v. 12, n. 3, p.164-214, 1995.

OSBORNE, J. F., BLACK, P. Young children's (7-11) ideas about light and their development, International Journal of Science Education, vol. 15, $\mathrm{n}^{\text {o. }}$ 1, p. 83-93, 1993.

ROCHA, José Fernando Moura. Origem e Evolução do Eletromagnetismo. In: ROCHA, José Fernando Moura (org). Origens e Evolução das Idéias da Física. Salvador: EDUFBA, 2002.

ROSA. L.P. A Revolução Científica e o Determinismo Newtoniano. In: Tecnociências e humanidades: novos paradigmas, velhas questões. O determinismo newtoniano na visão de mundo moderno. Vol. 1. São Paulo: Paz e Terra, 2005.

SILVA, Márcia Gorette Lima; SILVA, Antônia Francimar; NUÑEZ, Isauro Beltrán. Dos modelos de mudança conceitual à aprendizagem como pesquisa orientada. In: NUÑEZ, Isauro Beltrán (org); RAMALHO, Betânia Leite. Fundamantos do EnsinoAprendizagem das Ciências Naturais e da Matemática: o novo ensino médio. Natal: Editora Salina, 2004.

SILVA, B. V. C. A popularização na ciência: a óptica de Newton no século XVIII. Holos (Online), v. 3, p. 95-104, 2008.

. Young fez, realmente, o experimento da fenda dupla?. Latin American Journal Physics. Education., v. 3, p. 280-287, 2009a.

; MARTINS, A.F.P. Enxergando o invisível: uma estratégia para discutir os modelos de visão apresentados por estudantes do ensino médio. In: Encontro de Pesquisa Educacional do Norte e do Nordeste. Anais do 19 EPENN, p.1-14, 2009a. 
Júri simulado: um uso da História e Filosofia da Ciência no

ensino da Óptica. Física na Escola, v. 10, p. 17-20, 2009b.

SOLBES, J; TRAVER, M.J. La utililización de la historia de las ciencias em la enseñanza de la física y de la química. Enseñanza de las Ciencias. v.14, p.103-112, 1996.

SOUZA, José de Arimater. Uma abordagem histórica para o ensino do princípio da inércia. Dissertação de Mestrado. 2008. Programa de Pós-Graduação em Ensino de Ciências Naturais e Matemática do Centro de Ciências Exatas e da Terra da Universidade Federal do Rio Grande do Norte, UFRN, Universidade Federal do Rio Grande do Norte, Natal.

VANNUCCHI, Andréa Infantosi. História e Filosofia da Ciência: da teoria para a sala de aula. 1996. Dissertação de Mestrado apresentada ao Instituto de Física e à Faculdade de Educação da USP, Universidade de São Paulo, São Paulo. 